\title{
Soil Carbon Stock and Flux in Plantation Forest and Grassland Eco- systems in Loess Plateau, China
}

\author{
HU Chanjuan ${ }^{1}$, LIU Guohua ${ }^{2}$, FU Bojie ${ }^{2}$, CHEN Liding ${ }^{2}$, LYU Yihe ${ }^{2}$, GUO Lei ${ }^{1}$ \\ (1. Institute of Geographical Science, Henan Academy of Sciences, Zhengzhou 450052, China; 2. State Key Laboratory of Urban and \\ Regional Ecology, Research Center for Eco-Environmental Sciences, Chinese Academy of Sciences, Beijing 100085, China)
}

\begin{abstract}
Carbon sequestration occurs when cultivated soils are re-vegetated. In the hilly area of the Loess Plateau, China, black locust (Robinia pseudoacacia) plantation forest and grassland were the two main vegetation types used to mitigate soil and water loss after cultivation abandonment. The purpose of this study was to compare the soil carbon stock and flux of these two types of vegetation which restored for 25 years. The experiment was conducted in Yangjuangou catchment in Yan'an City, Shaanxi Province, China. Two adjacent slopes were chosen for this study. Six sample sites were spaced every $35-45 \mathrm{~m}$ from summit to toe slope along the hill slope, and each sample site contained three sampling plots. Soil organic carbon and related physicochemical properties in the surface soil layer $(0-10 \mathrm{~cm}$ and $10-20 \mathrm{~cm})$ were measured based on soil sampling and laboratory analysis, and the soil carbon dioxide $\left(\mathrm{CO}_{2}\right)$ emissions and environmental factors were measured in the same sample sites simultaneously. Results indicated that in general, a higher soil carbon stock was found in the black locust plantation forest than that in grassland throughout the hill slope. Meanwhile, significant differences in the soil carbon stock were observed between these two vegetation types in the upper slope at soil depth $0-10 \mathrm{~cm}$ and lower slope at soil depth $10-20 \mathrm{~cm}$. The average daily values of the soil $\mathrm{CO}_{2}$ emissions were $1.27 \mu \mathrm{mol} /\left(\mathrm{m}^{2} \cdot \mathrm{s}\right)$ and $1.39 \mu \mathrm{mol} /\left(\mathrm{m}^{2} \cdot \mathrm{s}\right)$ for forest and grassland, respectively. The soil carbon flux in forest covered areas was higher in spring and less variation was detected between different seasons, while the highest carbon flux was found in grassland in summer, which was about three times higher than that in autumn and spring. From the carbon sequestration point of view, black locust plantation forest on hill slopes might be better than grassland because of a higher soil carbon stock and lower carbon flux.
\end{abstract}

Keywords: soil organic carbon; soil carbon dioxide $\left(\mathrm{CO}_{2}\right)$ emissions; vegetation restoration; Loess Plateau

Citation: Hu Chanjuan, Liu Guohua , Fu Bojie, Chen Liding, Lyu Yihe, Guo Lei, 2014. Soil carbon stock and flux in plantation forest and grassland ecosystems in Loess Plateau, China. Chinese Geographical Science, 24(4): 423-435. doi: 10.1007/s11769-014-0700-7

\section{Introduction}

Carbon dioxide $\left(\mathrm{CO}_{2}\right)$ is a main greenhouse gas that contributes to global warming, and it is a big part of the discussion on climate change in the scientific and political communities. Compared to annual emissions of $\mathrm{CO}_{2}$ from fossil fuel combustion, the natural fluxes of $\mathrm{CO}_{2}$ are much higher (Singh et al., 2010). Soil is considered to be a huge carbon pool, which has stored $1.5 \times 10^{18} \mathrm{~g}$ of organic carbon, about twice as much as the carbon found in the atmosphere and three times the quantity found in vegetation (Schlesinger, 1997). Therefore, tiny changes in the soil carbon pool could have serious impacts on the $\mathrm{CO}_{2}$ content of the atmosphere. How to increase soil carbon sequestration seems to be an important question in reducing $\mathrm{CO}_{2}$ emissions and mitigating climate change.

Land use and cover change affect carbon sequestration. Deforestation, biomass burning, conversion of a natural to an agricultural ecosystem, and soil cultivation

Received date: 2013-10-16; accepted date: 2014-01-06

Foundation item: Under the auspices of National Basic Research Program of China (No. 2007CB407205), National Natural Science Foundation of China (No. 40871085)

Corresponding author: LIU Guohua. E-mail: ghliu@rcees.ac.cn

(C) Science Press, Northeast Institute of Geography and Agroecology, CAS and Springer-Verlag Berlin Heidelberg 2014 
could contribute greatly to increase in atmosphere $\mathrm{CO}_{2}$. Lal (2004) reported that the reduction in the soil organic carbon pool contributed $78 \pm 12 \mathrm{Pg}$ of carbon (C) to the atmosphere and some cultivated soils have lost one half to two thirds of the original soil organic carbon (SOC) pool, with a cumulative loss of $30-40 \mathrm{Mg} \mathrm{C} / \mathrm{ha}$. Soil disturbance resulting from agriculture and other land uses could stimulate the decomposition rate of organic carbon and increase net emissions of $\mathrm{CO}_{2}$ to the atmosphere (Smith et al., 2008). The conversion of the native ecosystem to agriculture could result in soil carbon loss, and vice versa after abandoned cultivation, afforestation, and reforestation induce carbon sequestration by increasing aboveground biomass and soil carbon input. The soil carbon stock increased by $19 \%$ and $18 \%$ after land use conversion from crop to pasture and plantation, respectively (Guo and Gifford, 2002). The difference in the soil carbon content is also quantified during land use change between plantation forest and pasture (Scott et al., 1999). Therefore, the carbon stock and flux information resulting from land use changes are vital for understanding the global carbon cycle.

In order to solve soil erosion problem in the Loess Plateau, the Chinese Government established many soil bio-engineering programs, especially the latest 'Grain for Green' (GFG) program initiated in the late 1990s. Many slope farmlands have been changed into grassland or forestland. Slope cultivation abandonment and reforestation in this area are effective in preventing soil erosion as well as reducing water and nutrient losses ( $\mathrm{Fu}$ et al., 2004; Zheng, 2006). Moreover, the implementation of GFG program is also an effective way to offset the increase in atmospheric $\mathrm{CO}_{2}$ (Zhang et al., 2009). Several studies on the effects of land use change on soil erosion and nutrients have been focused on the Loess Plateau (Wang et al., 2001; Gong et al., 2006; Fu et al., 2009). However, there is a continuing debate on which of the two main restoration vegetation types, plantation forest or grass, is better for carbon sequestration in the restoration of this area. Peng et al. (2006) and Wang et al. (2007) reported that both plantation forest and grass could significantly improve the soil organic carbon content, as they hold $117.7 \%$ and $39.4 \%$ more than that found in farmland after cultivation abandonment, respectively. Gong et al. (2006) found that soil organic matter was significantly higher in forest than in artificial grassland. In contrast, Yang and Rong (2007) observed that soil organic carbon was lower for plantation forest than for grassland. Therefore, there is no consistent conclusion on this issue to date.

Most studies on the comparison of soil carbon in plantation forest and grassland in this area are at the sample site scale. However, topography could influence other environmental factors, such as temperature, water, and nutrients, which control the soil carbon cycling process (Hishi et al., 2004; Fang et al., 2009). Along hill slopes, the soil carbon would have different distribution trends under different vegetation types. Whether the results are the same at the hill slope scale and how soil carbon varies along the slope in two typical ecosystems are not well understood. In addition, researches have consistently been focused on the soil carbon stock but little attention has been paid to soil carbon emissions, which are an important influence on the efficiency of soil carbon sequestration. Therefore, the objectives of this study were to compare the two typical vegetation types, plantation forest and grass, in terms of carbon stock and flux not only at the sample site scale, but also at the hill slope scale, and to find the main factors impacting carbon stock and flux in this semi-arid area.

\section{Materials and Methods}

\subsection{Study area}

The study area is located in the Yangjuangou watershed $\left(36^{\circ} 42^{\prime} \mathrm{N}, 109^{\circ} 31^{\prime} \mathrm{E}\right)$ in Yan'an City, Shaanxi Province, China (Fig. 1). The area of this watershed is $2.02 \mathrm{~km}^{2}$ with an elevation of 1025-1250 m above sea level. The average annual precipitation is $550 \mathrm{~mm}$, and most of the precipitation occurs between July and September. The soil is classified as Calcaric Cambisols, is readily susceptible to soil erosion, and has a texture ranging from fine silt to silt (Fu et al., 2000; Hu et al., 2010).

\subsection{Soil sampling}

In order to reduce soil loss, slope cultivation was abandoned in the study area in the 1980s. Black locust plantation forest and wild grass were the two main vegetation types used after the abandonment of agriculture. In this study, two adjacent slopes with forest (F) and grass $(\mathrm{G})$ that had been restored for 25 years were chosen. For the two slopes, they had similar cultivated history before agriculture abandoned. Six sites, 


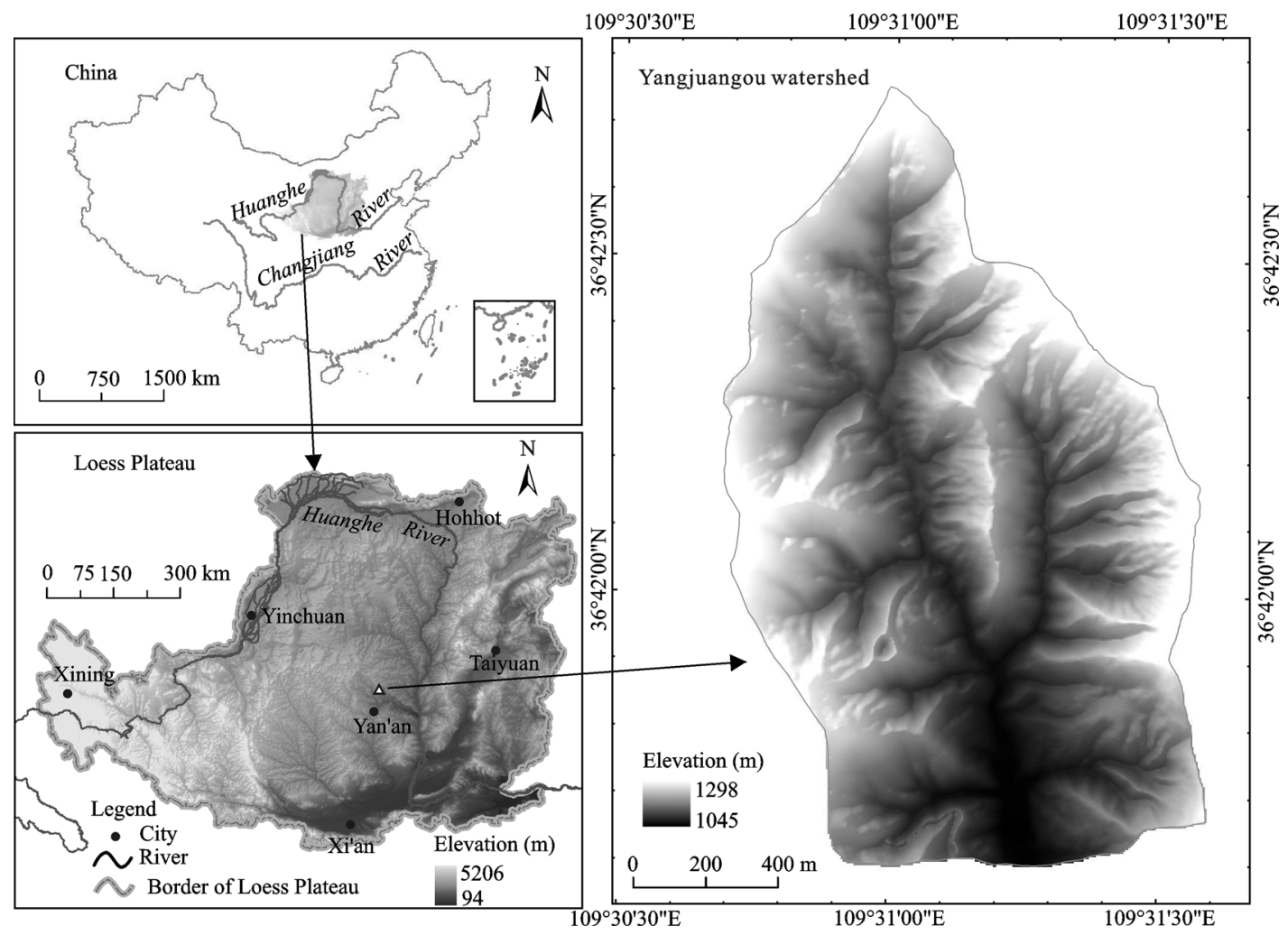

Fig. 1 Location of study area

with three plots at each site, were sampled along the slope from summit to toe. Sample sites were spaced every 35-45 $\mathrm{m}$ along the slope. The area of each sample site was about $200 \mathrm{~m}^{2}$, and the area of each sampling plot was $25 \mathrm{~m}^{2}$.

Five soil cores (at depths of $0-10 \mathrm{~cm}$ and $10-20 \mathrm{~cm}$, $3.5 \mathrm{~cm}$ in diameter) were randomly collected from each sampling plot in August 2007, October 2007, and May 2008. The soil samples were gently mixed, stored in sealed, insulated plastic bags to prevent moisture loss, and kept on ice for transport to the laboratory. The soil sample was sieved through a 2-mm screen mesh under field-moisture conditions and stored at $4^{\circ} \mathrm{C}$ for microbial properties analysis. Subsamples of each soil sample were air-dried for soil $\mathrm{pH}$ and electrical conductivity analysis, and sieved through a $0.145-\mathrm{mm}$ screen mesh for soil organic carbon and total nitrogen analysis.

\subsection{Analysis of soil physicochemical and microbial properties}

Soil water content (SWC), bulk density (BD), $\mathrm{pH}$, electrical conductivity (EC), and soil total nitrogen (TN) were analyzed for soil samples from each sampling plot (Table 1). Soil microbial biomass carbon (Cmic) was also studied. The detailed methods and results of soil physicochemical and microbial properties were presented in Hu et al. (2010).

\subsection{Analysis of soil organic carbon and calculation of soil carbon stock}

Soil organic carbon was determined by the $\mathrm{K}_{2} \mathrm{Cr}_{2} \mathrm{O}_{7}$ titration method after digestion (Lu, 1999), and the soil carbon stock $\left(\mathrm{g} / \mathrm{m}^{2}\right)$ was calculated by using the following equation for each sample depth (Lemenih and Itanna, 2004):

Soil $C=z \times \rho_{\mathrm{b}} \times c \times 10$

where $z$ is the thickness of each sample depth $(\mathrm{cm}), \rho_{\mathrm{b}}$ is the bulk density of each sample depth $\left(\mathrm{g} / \mathrm{cm}^{3}\right)$, and $c$ is the organic carbon concentration of each sample depth $(\mathrm{g} / \mathrm{kg})$.

\subsection{Measurement of soil $\mathrm{CO}_{2}$ emissions}

Soil $\mathrm{CO}_{2}$ emissions were measured with a LI-COR soil $\mathrm{CO}_{2}$ emissions chamber (model LI-8100; LI-COR Biosciences, Lincoln, Nebraska) and a LI-8100 infrared gas analyzer (LI-COR Biosciences, Lincoln, Nebraska). Five soil collars were positioned randomly in each plot, with fifteen collars for each site. The litterfall layer was removed before measurement. The measurements were conducted from 09:00 to 17:00 with a monitoring fre- 
Table 1 Soil physicochemical and microbial properties under forest and grassland

\begin{tabular}{|c|c|c|c|c|c|c|c|}
\hline Soil depth & Site & $\mathrm{TN}(\mathrm{g} / \mathrm{kg})$ & $\mathrm{pH}$ & $\mathrm{EC}(\mu \mathrm{s} / \mathrm{cm})$ & $\mathrm{BD}\left(\mathrm{g} / \mathrm{cm}^{3}\right)$ & SWC (\%) & Cmic $(\mathrm{mg} / \mathrm{kg})$ \\
\hline \multirow{12}{*}{$0-10 \mathrm{~cm}$} & $\mathrm{~F} 1$ & 0.60 & 8.15 & 158.03 & 1.10 & 3.91 & 222.29 \\
\hline & $\mathrm{F} 2$ & 0.85 & 8.12 & 192.47 & 1.14 & 6.48 & 348.81 \\
\hline & $\mathrm{F} 3$ & 0.71 & 8.16 & 164.83 & 1.10 & 5.18 & 174.54 \\
\hline & $\mathrm{F} 4$ & 0.67 & 8.31 & 147.03 & 1.17 & 5.43 & 273.50 \\
\hline & F5 & 0.51 & 8.22 & 148.33 & 1.20 & 4.37 & 227.12 \\
\hline & F6 & 0.49 & 8.32 & 130.57 & 1.27 & 4.24 & 174.25 \\
\hline & G1 & 0.50 & 8.13 & 177.00 & 1.21 & 9.55 & 147.37 \\
\hline & G2 & 0.56 & 8.16 & 178.90 & 1.26 & 9.82 & 148.56 \\
\hline & G3 & 0.58 & 8.14 & 152.13 & 1.24 & 8.04 & 187.00 \\
\hline & G4 & 0.61 & 8.11 & 174.33 & 1.23 & 8.82 & 212.03 \\
\hline & G5 & 0.67 & 8.13 & 171.47 & 1.26 & 8.57 & 276.20 \\
\hline & G6 & 0.65 & 8.05 & 289.97 & 1.28 & 9.02 & 293.18 \\
\hline \multirow{12}{*}{$10-20 \mathrm{~cm}$} & $\mathrm{~F} 1$ & 0.41 & 8.27 & 154.13 & 1.16 & 7.12 & 67.39 \\
\hline & $\mathrm{F} 2$ & 0.59 & 8.26 & 171.63 & 1.14 & 8.05 & 164.46 \\
\hline & $\mathrm{F} 3$ & 0.53 & 8.28 & 149.57 & 1.08 & 8.05 & 123.11 \\
\hline & $\mathrm{F} 4$ & 0.53 & 8.20 & 147.50 & 1.14 & 7.11 & 160.46 \\
\hline & F5 & 0.46 & 8.31 & 135.83 & 1.17 & 6.70 & 143.54 \\
\hline & F6 & 0.45 & 8.36 & 126.07 & 1.18 & 6.35 & 118.93 \\
\hline & G1 & 0.41 & 8.24 & 150.50 & 1.23 & 9.84 & 51.25 \\
\hline & $\mathrm{G} 2$ & 0.43 & 8.22 & 176.77 & 1.25 & 10.56 & 55.98 \\
\hline & G3 & 0.51 & 8.22 & 161.33 & 1.18 & 10.08 & 100.46 \\
\hline & G4 & 0.49 & 8.22 & 170.90 & 1.25 & 9.47 & 121.79 \\
\hline & G5 & 0.62 & 8.15 & 191.53 & 1.25 & 9.83 & 186.40 \\
\hline & G6 & 0.62 & 8.13 & 181.30 & 1.23 & 9.20 & 196.51 \\
\hline
\end{tabular}

Notes: TN, total nitrogen; EC, electrical conductivity; BD, bulk density; SWC, soil water content; Cmic, microbial biomass carbon. F1-F6 and G1-G6 indicate sample sites along forest and grassland slopes from summit to toe, respectively

quency of every 1 hour in August 2007 (summer), October 2007 (autumn), and May 2008 (spring). The value of soil $\mathrm{CO}_{2}$ emissions rate for each site was the average of fifteen measuring values.

\subsection{Measurement of environmental factors}

Environmental factors, including air temperature, air moisture, soil temperature, and soil water content (\%), were measured at the same time when the soil $\mathrm{CO}_{2}$ emissions were measured. The portable Testo-615 (Germany, $\pm 0.5^{\circ} \mathrm{C}$ ) was used to monitor air temperature and moisture at the soil surface ( $5 \mathrm{~cm}$ above floor). The soil temperature was measured at $5 \mathrm{~cm}$ soil depth with a soil temperature probe (LI-COR Inc., Nebraska, USA, $\pm 1.5^{\circ} \mathrm{C}, 0^{\circ} \mathrm{C}-50^{\circ} \mathrm{C}$ ), and A Time domain reflectometry
(TDR) probe (ML2X, England, $\pm 0.01 \%, 0{ }^{\circ} \mathrm{C}-40^{\circ} \mathrm{C}$; $\pm 0.02 \%, 40^{\circ} \mathrm{C}-70^{\circ} \mathrm{C}$ ) was used for detecting the volumetric soil moisture content.

\subsection{Data analysis}

SPSS Version 11.0 and CANOCO software was used for the data analysis. Significant differences in soil properties between the two vegetation types were determined using t-tests, and those among different slope positions were determined using one-way ANOVA. Differences at the $p<0.05$ level were considered to be statistically significant using the least significant differences (LSD) test. Redundancy analysis (RDA) was used to elucidate the relationships between soil carbon stock, soil physicochemical properties, and soil microbial properties. 
Regression analysis was used to evaluate the contribution of soil temperature and soil water content to soil $\mathrm{CO}_{2}$ emissions, and the relationship among soil $\mathrm{CO}_{2}$ emissions and the impact factors was quantified by using correlation analysis.

\section{Results}

\subsection{Soil carbon stock}

Along the slope, soil carbon stock had different variation trends from the summit to toe slope in the forest and grassland areas (Fig. 2). The soil carbon stock had a clearly increasing trend in the grassland slope except for G6 site. The average concentration of soil organic carbon in the forest area was $6.39 \mathrm{~g} / \mathrm{kg}$ at $0-10 \mathrm{~cm}$ and $4.85 \mathrm{~g} / \mathrm{kg}$ at $10-20 \mathrm{~cm}$; the values were higher than those in the grassland area $(5.57 \mathrm{~g} / \mathrm{kg}$ and $4.69 \mathrm{~g} / \mathrm{kg}$ for $0-10 \mathrm{~cm}$ and

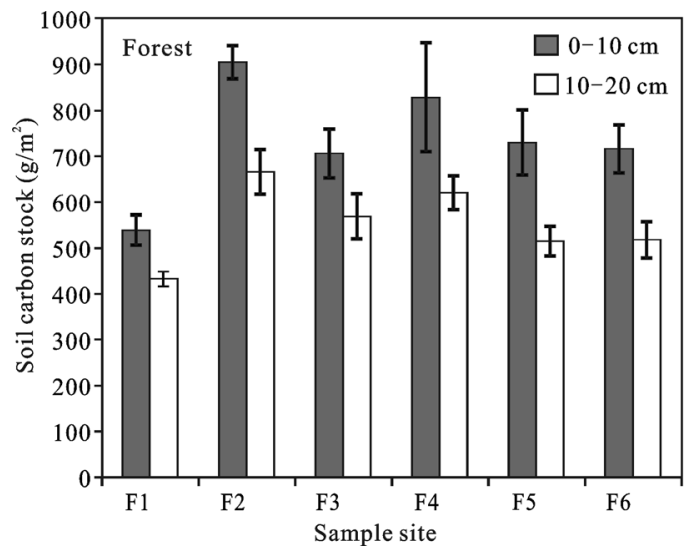

10-20 cm, respectively). The average soil carbon stock of 0-20 cm depth in the forest was $1292 \mathrm{~g} / \mathrm{m}^{2}$ while that of the grassland was $1274 \mathrm{~g} / \mathrm{m}^{2}$. There was no significant difference between the forest and grassland in the soil organic carbon stock at the slope scale. However, there was a significant difference between the two vegetation types at different slope positions. The forest had a higher soil carbon stock on the upper and middle slopes than that of grassland, while the soil carbon stock was higher at the lower slope of grassland than that of forest. A significant difference was observed at the upper slope for the $0-10 \mathrm{~cm}$ depth and at the lower slope for the 10-20 cm depth (Fig. 3). The results of Univariate ANOVA analysis indicated that slope position and the interaction of vegetation and slope position could significantly impact the soil carbon stock of forest and grassland slopes.

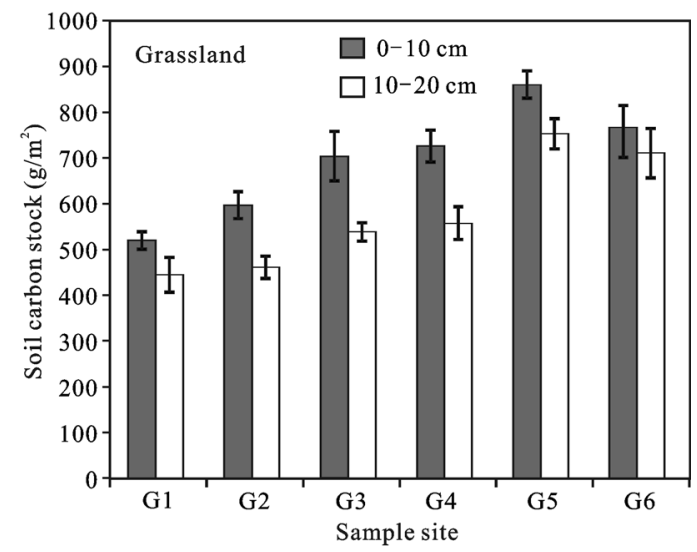

Fig. 2 Soil carbon stock in each sample site along hill slope under forest and grassland. F1-F6 and G1-G6 indicate sample sites along forest and grassland slopes from summit to toe, respectively
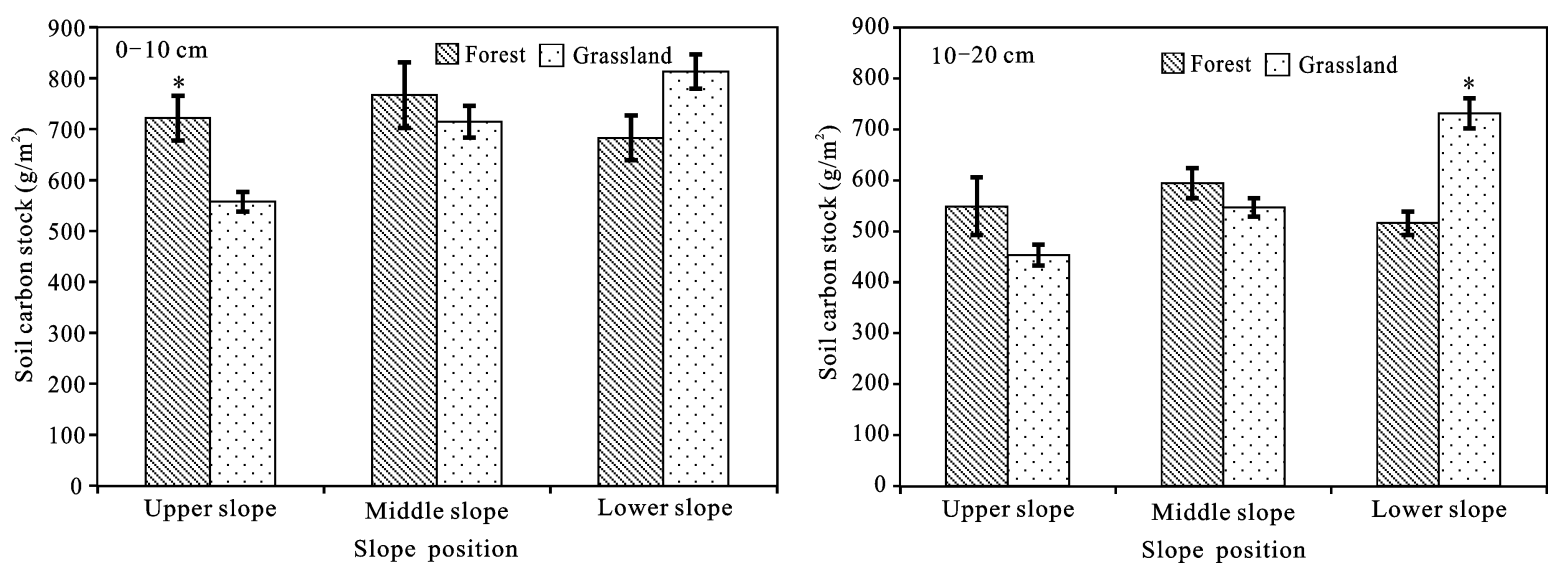

Fig. 3 Difference of soil carbon stock between forest and grassland at different slope positions. * indicates significant difference at 0.05 level 


\subsection{Soil $\mathrm{CO}_{2}$ emissions}

The diurnal variation of soil $\mathrm{CO}_{2}$ emissions in different sample sites along the slope under the two vegetation types are shown in Fig. 4 and Fig. 5. In spring, which is a dry season, both of the two vegetation types had a generally same diurnal dynamics of a decrease from 09:00 to 17:00. In summer, excepted for the maximum values of soil $\mathrm{CO}_{2}$ emissions in $\mathrm{F} 2$ site appeared in 16:00, the soil $\mathrm{CO}_{2}$ emissions of other forest sites had a decreasing trend from morning to afternoon and the maximum value appeared in 09:00-11:00. In autumn, with the exception of F2, the diurnal variation of soil $\mathrm{CO}_{2}$ emissions under forest first increased and reached a peak between 11:00-13:00, and then declined. For grassland ecosystem, the diurnal variation of soil $\mathrm{CO}_{2}$ emissions during the summer and autumn showed a similar law and the maximum value appeared between

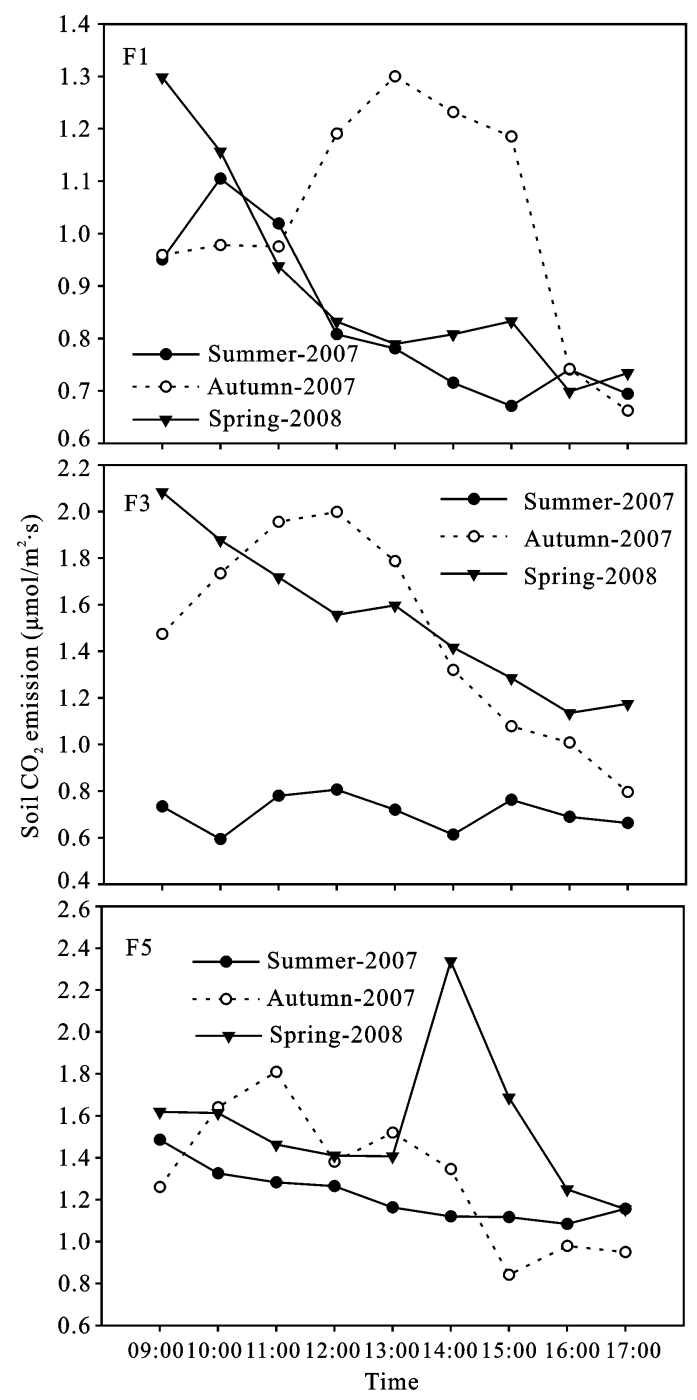

12:00-14:00. In addition, compared to grassland ecosystem, the soil $\mathrm{CO}_{2}$ emissions under forest ecosystem had more difference among sample sites along the slope.

The seasonal dynamics of soil $\mathrm{CO}_{2}$ emissions were shown in Fig. 6. The soil $\mathrm{CO}_{2}$ emissions was higher in spring for the forest, with minor variations among the different seasons. The grassland had the highest soil $\mathrm{CO}_{2}$ emissions in summer, which was about three times higher than that of autumn and spring. For the whole slope, the average daily values of soil $\mathrm{CO}_{2}$ emissions were $1.27 \mu \mathrm{mol} /\left(\mathrm{m}^{2} \cdot \mathrm{s}\right)$ and $1.39 \mu \mathrm{mol} /\left(\mathrm{m}^{2} \cdot \mathrm{s}\right)$ for the forest and grassland, respectively. Along the hill slope, the average soil $\mathrm{CO}_{2}$ emissions increased from the upper slope to the lower slope in both of the two ecosystems. However, as shown in Fig. 6, the trends of soil $\mathrm{CO}_{2}$ emissions along the slope were unlike in different seasons.

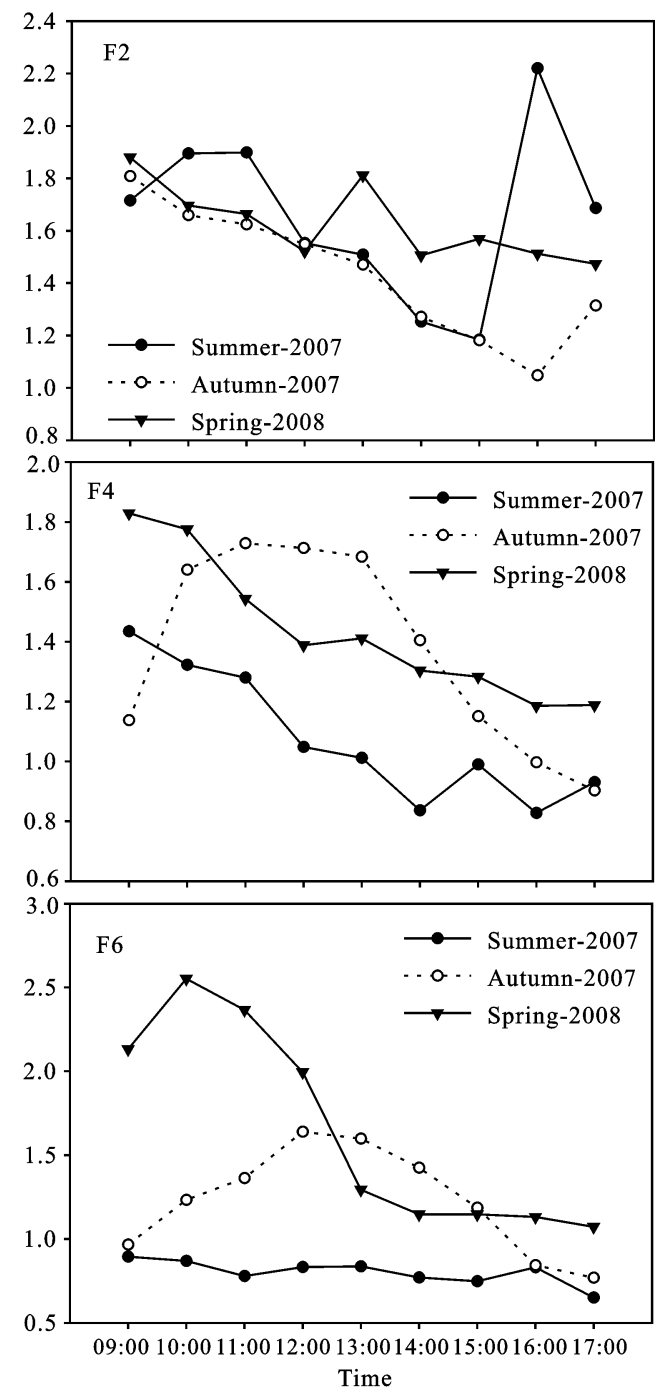

Fig. 4 Diurnal dynamics of soil $\mathrm{CO}_{2}$ emissions under forest. F1-F6 indicate sample sites along forest slopes from summit to toe 

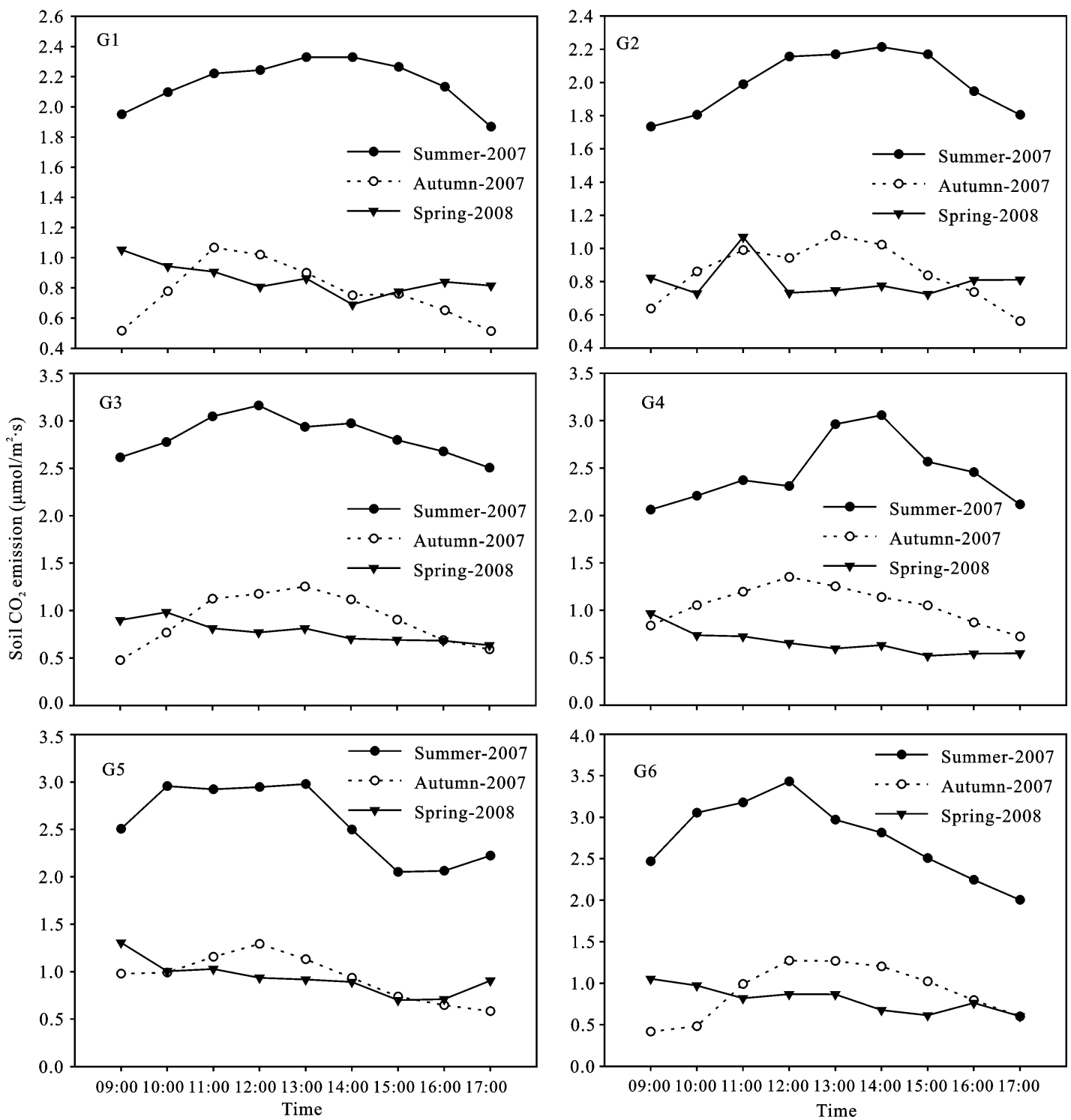

Fig. 5 Diurnal dynamics of soil $\mathrm{CO}_{2}$ emissions under grassland. G1-G6 indicate sample sites along grassland slopes from summit to toe
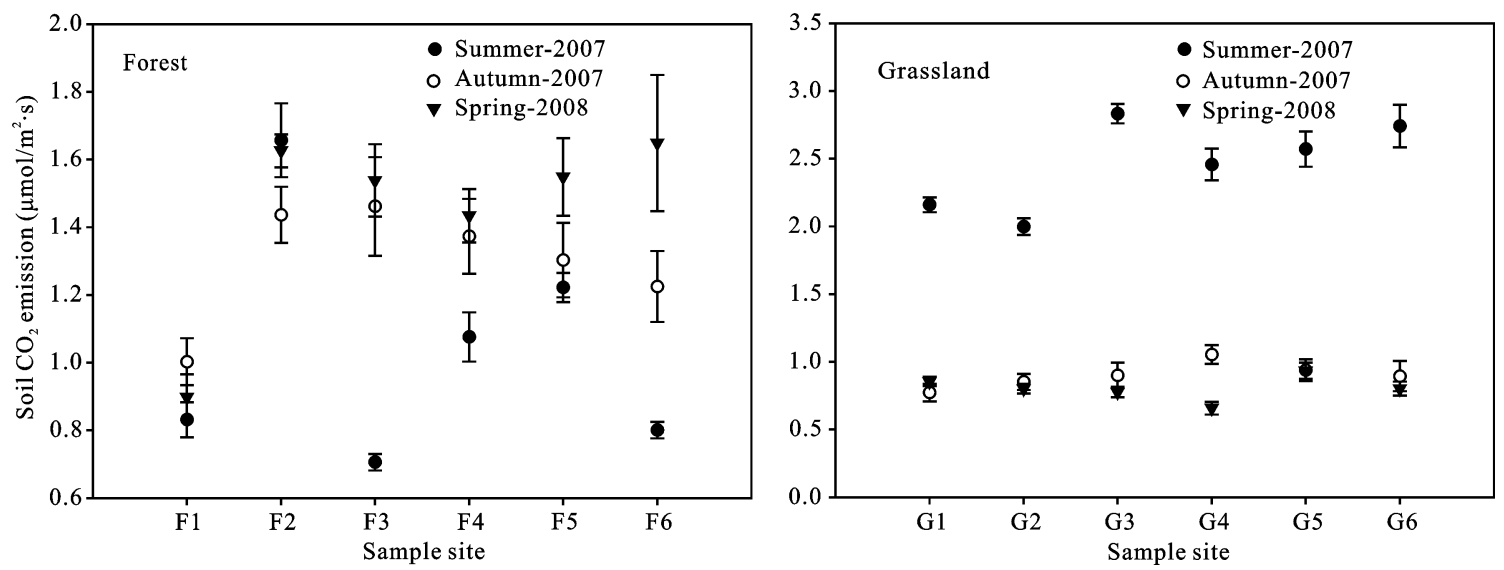

Fig. 6 Seasonal dynamics of soil $\mathrm{CO}_{2}$ emissions in forest and grassland. F1-F6 and G1-G6 indicate sample sites along forest and grassland slopes from summit to toe, respectively 


\subsection{Main factors impacting soil carbon stock and soil $\mathrm{CO}_{2}$ emissions}

\subsubsection{Relationship between soil carbon stock and other soil properties}

All sampling plots data were used to analyze the relationship between soil carbon stock and other soil properties. As shows in Fig. 7, arrows that have the same direction (the angle between the two arrows is lower than $90^{\circ}$ ) show that the two variables had a positive correlation. On the other hand, projection points moving in opposite directions imply a negative correlation of the two variables. A projection point near the coordinate origin (zero point) suggests that the two variables have a low correlation. Each arrow points in the expected direction of the steepest increase of impact factor values. For both of the two vegetation types, the TN and Cmic which had lower angles with soil carbon stock arrows and longer distance from the zero point had stronger relationship with soil carbon stock than other impact factors did.

\subsubsection{Relationship between soil $\mathrm{CO}_{2}$ emissions and impact factors}

All monitored data in each sample site from 09:00 to 17:00 were used to detect the relationship between soil temperature, soil water content, and soil $\mathrm{CO}_{2}$ emissions (Fig. 8). Compared to the forest, soil $\mathrm{CO}_{2}$ emissions had a more clear relationship with soil temperature and soil water content in the grassland. For both of the ecosystems, the fit model of soil $\mathrm{CO}_{2}$ emissions with soil tem- perature and soil water content was quadratic. Moreover, in the forest, a significant relationship exists between soil $\mathrm{CO}_{2}$ emissions and soil water content when the soil water content exceeds $15 \%$, and only in spring the soil temperature significantly correlated with soil $\mathrm{CO}_{2}$ emissions.

Correlations of soil organic carbon, soil microbial biomass, air temperature, and air moisture with soil $\mathrm{CO}_{2}$ emissions were also analyzed. The results showed that soil organic carbon and air moisture had significant correlations with soil $\mathrm{CO}_{2}$ emissions $(p<0.05)$ in the forest, and soil $\mathrm{CO}_{2}$ emissions was positively significantly correlated with air temperature and air moisture in the grassland $(p<0.05)$

\section{Discussion}

\subsection{Soil carbon stock and impact factors}

In the eroded area, soil carbon stock could be increased due to soil erosion mitigation (Lal, 2002), an increase in organic matter inputs (Smith, 2008), a decrease in organic matter weathering, or microbial breakdown (Lal, 2005) during the vegetation restoration process. In this study, a higher soil carbon stock was found in the forest ecosystem than the grassland ecosystem on a slope scale although the difference was not statistically significant for the slope as a whole. This result is consistent with the findings of Post and Kwon (2000), who reported that the average accumulation rates of soil
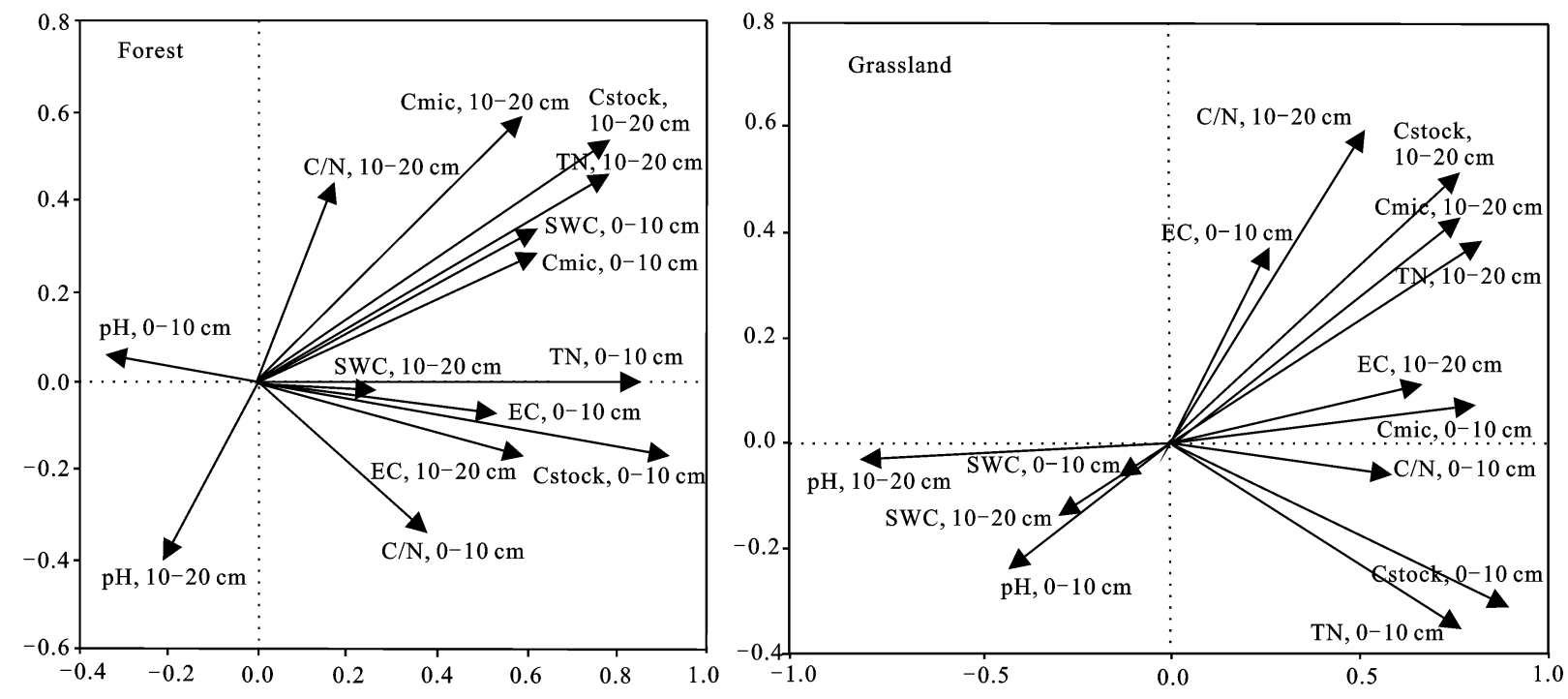

Fig. 7 Relationship between soil carbon stock and impact factors. Cstock: soil organic carbon stock; TN: total nitrogen; Cmic: soil microbial biomass carbon; SWC: soil water content; EC: electrical conductivity; C/N: soil organic carbon/total nitrogen 

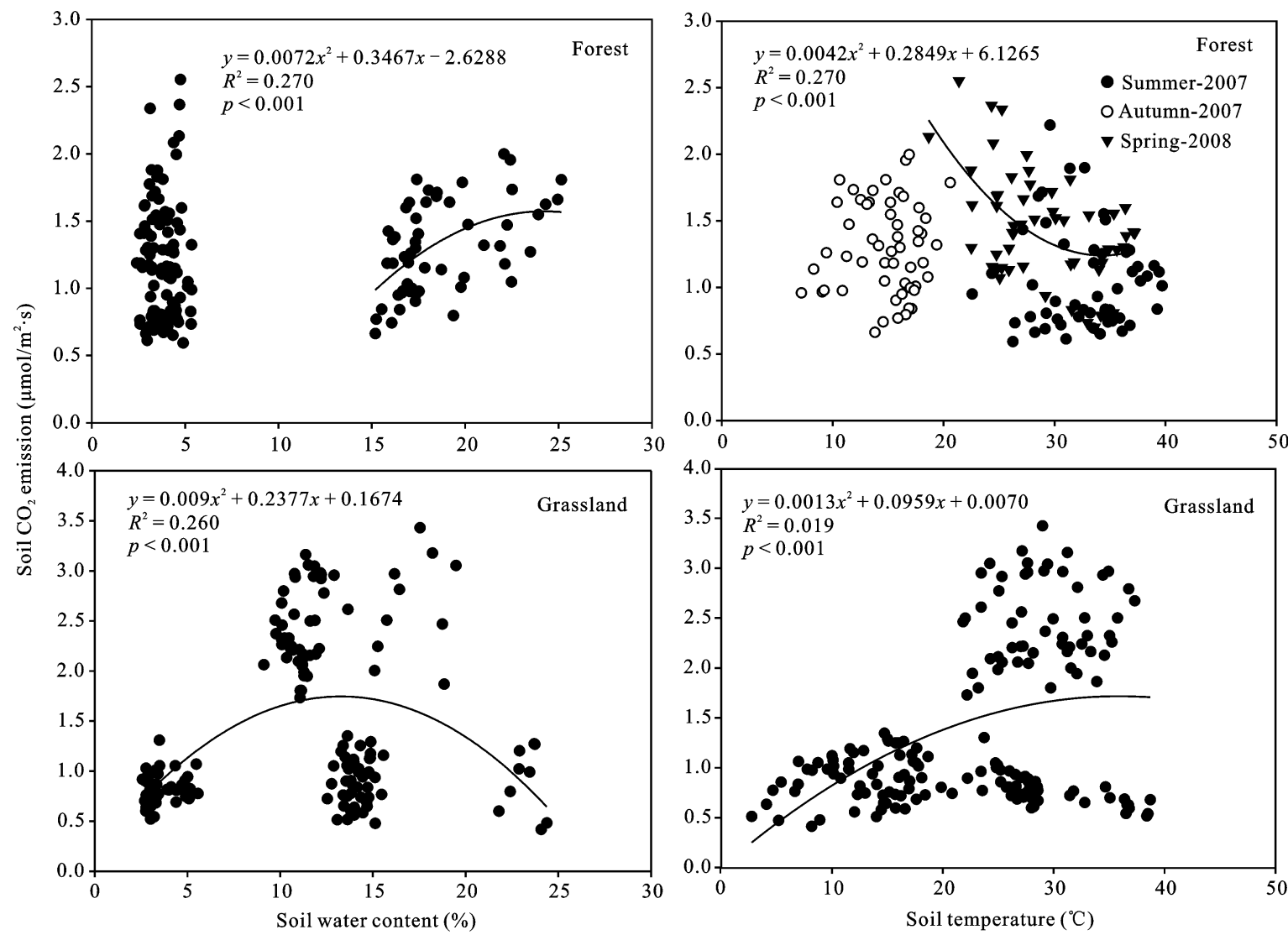

Fig. 8 Relationship between soil temperature, soil water content and soil $\mathrm{CO}_{2}$ emissions

carbon are similar for forest and grassland established from farmland. Nevertheless, different results at different slope positions were also found for these two ecosystems and the results showed slope position explained most of the variance of soil carbon stock. Compared to grassland, forest had a higher soil carbon stock at the upper and middle slopes. In this area, soil erosion was a serious problem and these water and soil movement processes could impact the soil carbon redistribution on the hill slope. The soil carbon, which centralizes in surface soil and is of low density, is prone to removal from surface runoff (Bajracharya et al., 2000; Lal, 2003). The different vegetation types and patterns on the slope would induce a different soil erosion process ( $\mathrm{Fu}$ et al., 2000; 2009), and this may be one reason for the variations in soil carbon along the hill slope of the forest and grassland in this study. From the erosion point of view, black locust forest might be better for decreasing soil erosion at upper and middle slope on some degree.

There is a close correlation between the environment above ground and below ground (Hooper et al., 2000; Wardle et al., 2004). Vegetation restoration could not only increase carbon storage through aboveground biomass, but also increase the carbon content in the soil ecosystem through litter and root decomposition. Litterfall and roots, especially fine roots, were the most important sources for soil carbon inputs. In another study on the Loess Plateau, the litterfall quantity of the forest was higher than that in grassland, a significant correlation was observed between litter accumulation and the soil organic carbon content of the soil layer from 0-20 $\mathrm{cm}$ (Guo et al., 2009), and fine root biomass in this area had the same variations in the two ecosystems (Chang et al., 2012). In this study, the forest had a lower soil carbon emission than that of the grassland. Higher carbon inputs and lower carbon outputs could induce more soil carbon accumulation.

Soil physicochemical and biological properties are also important factors impacting soil carbon sequestration. The results of correlation analysis indicated that the soil $\mathrm{TN}$ and $\mathrm{Cmic}$ were the main factors influencing soil carbon stock for both vegetation types. Nitrogen availability is crucial for carbon sequestration. High substrate nitrogen concentrations inhibit lignin-degrading en- 
zymes, promoting humification, and thereby limit soil organic matter decomposition (Berg, 2000; DeForest et al., 2004). The black locust plantation forest in our study is N-fixing vegetation, and Resh et al. (2002) reported that the $\mathrm{N}$-fixing plant could induce a higher soil carbon stock by not only increasing new carbon but also maintaining older carbon. As an important decomposer, microbial organisms make vital contributions during soil carbon formation. A significant correlation is found between soil carbon and microbial biomass (Palma et al., 2000). Higher soil microbial biomass could accelerate the soil carbon turnover rate and lead to more carbon accumulation. Therefore, higher nitrogen content and microbial biomass might be induce to higher soil carbon stock in the area which covered by black locust forest.

\subsection{Soil $\mathrm{CO}_{2}$ emissions and impact factors}

Soil $\mathrm{CO}_{2}$ emissions are an important part of the carbon cycle. Because of the relationship between greenhouse gases, especially $\mathrm{CO}_{2}$ and global warming, soil $\mathrm{CO}_{2}$ emissions have been studied in many ecosystems and districts. However, the basic data of soil $\mathrm{CO}_{2}$ emissions in semiarid areas is insufficient. The study of soil carbon flux in the Loess Plateau is vital not only in supplying basic data for semi-arid areas, but also in providing a useful foundation for soil carbon sequestration assessment after land use change from an agroecosystem to a forest ecosystem, especially as a result of large area reforestation. Moreover, the afforestation of former farmlands has been acknowledged as a land use change that contributes to the mitigation of atmospheric $\mathrm{CO}_{2}$ emissions (IPCC, 2000; Vesterdal et al., 2002). Forest and grassland are two main land use types after 'Grain to Green' Program implementation in the Loess Plateau of China, and the result of that soil $\mathrm{CO}_{2}$ emissions under different vegetation types were different in this area have been reported (Li Hongsheng et al., 2008). In this study, the mean soil carbon flux was higher in grassland than that in forest. Corre et al. (2002) found that poorly drained soils on the lower slopes generally have higher microbial respiration compared to well-drained soil on the upper slopes. A significant difference in soil respiration between different slope positions has previously been also reported in the Loess Plateau (Li Rong et al., 2008). In this study, different trends of soil carbon flux along the slope were found not only for different seasons but also for two vegetation types.
Soil respiration combines root and soil micro and macro-organism respiration, and is apt to be influenced by vegetation and many other environmental factors. In this study, the soil $\mathrm{CO}_{2}$ emissions of grassland had larger seasonal variations than those of forest. Grassland had higher soil $\mathrm{CO}_{2}$ emissions in summer, while higher values were found in spring for forest. Davidson et al. (2000) observed that grasses are productive in the wet season and senescent in the dry season, resulting in the largest seasonal amplitude of soil $\mathrm{CO}_{2}$ emissions, whereas deep-rooted forests were found to maintain substantial soil respiration during the dry season. In the study area, summer is the rainy season. Hearty root growth increasing the root respiration may induce higher soil $\mathrm{CO}_{2}$ emissions in grassland than forest, while the microbial biomass was found to be lower in grassland than forest in summer. Microbial respiration is an important part of soil respiration, especially in a semi-arid area. In the forest, a higher soil carbon flux was found in spring whereas the microbial biomass was also the highest in spring.

The study results have indicated that factors such as temperature, soil water content, and substrate properties have greater effects on soil respiration than vegetation (Raich and Tufekcioglu, 2000). Soil temperature and soil water content are considered to be the factors most commonly related to temporal variations in $\mathrm{CO}_{2}$ efflux from soils. Generally, a temperature increase could stimulate soil $\mathrm{CO}_{2}$ emissions, and a temperature effect is always described as an exponential function (Lloyd and Taylor, 1994; Wu et al., 2006). However, a quadratic equation described the temperature effect in grassland, and a significant relationship was found only in spring for the forest. A study in arid central Washington State indicated that the effect of temperature on seasonal variation in $\mathrm{CO}_{2}$ efflux manifested only when the soil moisture was sufficient to permit significant root and microbial $\mathrm{CO}_{2}$ production (Wildung et al., 1975). In a semi-arid area, the soil water content can inhibit $\mathrm{CO}_{2}$ production in soils (Raich and Tufekcioglu, 2000). The annual precipitation is insufficient and soil water is always a limiting factor for vegetation in the Loess Plateau. From the diurnal dynamic of soil $\mathrm{CO}_{2}$ emissions and the relationship with soil temperature and soil water content in the two ecosystems, the restriction of soil water on soil carbon flux during the study period could be seen. In the dry spring season of this study, the soil 
$\mathrm{CO}_{2}$ emissions did not increase along with temperature but had a decreasing trend with soil water content decreasing during the measuring period for both forest and grassland. In summer and autumn, the highest soil $\mathrm{CO}_{2}$ emissions were observed in the high temperature period during the day, when the soil water was relatively sufficient. The soil carbon flux of grassland had a significant relationship with soil temperature might be due to relatively higher soil water content in grassland. The soil water content described by numerous quadratic equations was found to be fitted well for both ecosystems. However, the soil water content in the forest was low and when the values were lower than $5 \%$, there was no significant correlation between soil carbon flux and soil water content. Litterfall quantity, soil carbon, and microbial organisms could also significantly impact soil $\mathrm{CO}_{2}$ emissions. In our study, there was no strong correlation of soil carbon flux with temperature and soil water content in the forest, as with grassland, but a significant relationship was found between soil carbon content and soil carbon flux. For the forest, soil carbon contributes to $\mathrm{CO}_{2}$ production in the surface soil besides the environmental factors such as temperature and water content functions.

\section{Conclusions}

In the Loess Plateau, for the two main restoration vegetation types, black locust plantation forest seems to be better than grassland in carbon sequestration because of a higher carbon stock and lower soil carbon flux in the semi-arid, hilly Loess area. Along the hill slope, the soil carbon of grassland has an increasing trend from summit to toe slope, while a smaller variation in soil carbon is observed along the hill slope which covered by forest. The difference in the soil carbon stock between forest and grassland is dependent on slope position. As a whole, soil organic carbon stock in the forest was higher than that in grassland due to a higher TN content and microbial biomass, but there is a lower soil $\mathrm{CO}_{2}$ emissions in the forest. Compared to the forest, the soil $\mathrm{CO}_{2}$ emissions in the grassland has a stronger relationship with soil water content and soil temperature while there was a clear seasonal pattern of soil $\mathrm{CO}_{2}$ emissions in the grassland.

The use of plantation forest in semi-arid areas during vegetation restoration is disputed by researchers because of the higher water consumed. Water, as a limited factor in semi-arid area, must be considered. However, from the carbon sequestration point of view, the carbon sequestration contribution of plantation forest in the hilly area of Loess Plateau could not be ignored. In future studies, carbon-water trade-offs should be explored. Based on our study results, we suggest that not all of the areas restored by black locust plantation forest are better but appropriate forest plantation in the study area is necessary based on soil and water conservation as well as soil carbon sequestration. As soil water in semi-arid areas is limited, the use of both plantation forest and grassland could be considered, especially in the slope scale; forest planted on the upper and middle slopes seems to be a better choice according to our study.

\section{References}

Bajracharya R M, Lal R, Kimble J M, 2000. Erosion effects on carbon dioxide concentration and carbon flux from an Ohio Alfisol. Soil Science Society of America, 64(2): 694-700. doi: $10.2136 /$ sssaj2000.642694x

Berg B, 2000. Litter decomposition and organic matter turnover in northern forest soils. Forest Ecology Management, 133(1-2): 13-22. doi: 10.1016/S0378-1127(99)00294-7

Corre M D, Schnabel R R, Stout W L, 2002. Spatial and seasonal variation of gross nitrogen transformations and microbial biomass in a northeastern US grassland. Soil Biology Biochemistry, 34(4): 445-457. doi: 10.1016/S0038-0717(01)00198-5

Chang R Y, Fu B J, Liu G H et al., 2012. Effects of soil physicochemical properties and stand age on fine root biomass and vertical distribution of plantation forests in the Loess Plateau of China. Ecological Research, 27(4): 827-836. doi: 10. 1007/s11284-012-0958-0

Davidson E A, Verchot L V, Cattânio J Q et al., 2000. Effects of soil water content on soil respiration in forests and cattle pasture of eastern Amazonia. Biogeochemistry, 48(1): 53-69. doi: 10.1023/A:1006204113917

DeForest J L, Zak D R, Pregitzer K S et al., 2004. Atmospheric nitrate deposition and the microbial degradation of cellobiose and vanillin in a northern hardwood forest. Soil Biology and Biochemistry, 36(6): 965-971. doi: 10.1016/j.soilbio.2004. 02.011

Fang Y T, Gundersen P, Zhang W et al., 2009. Soil-atmosphere exchange of $\mathrm{N}_{2} \mathrm{O}, \mathrm{CO}_{2}$ and $\mathrm{CH}_{4}$ along a slope of an evergreen broad-leaved forest in southern China. Plant and Soil, 319(1-2): 37-48. doi: 10.1007/s11104-008-9847-2

Fu B J, Meng Q H, Qiu Y et al., 2004. Effects of land use on soil erosion and nitrogen loss in the hilly area of the Loess Plateau, China. Land Degradation and Development, 15(1): 87-96. doi: 10.1002/Idr.572

$\mathrm{Fu}$ B J, Chen L D, Ma K M et al., 2000. The relationships be- 
tween land use and soil conditions in the hilly area of the Loess Plateau in northern Shaanxi, China. Catena, 39(1): 69-78. doi: 10.1016/S0341-8162(99)00084-3

Fu B J, Wang Y F, Lü Y H et al., 2009. The effects of land use combination on soil erosion-A case study in Loess Plateau of China. Progress in Physical Geography, 33(6): 793-804. doi: 10.1177/0309133309350264

Gong J, Chen L D, Fu B J et al., 2006. Effect of land use on soil nutrients in the loess hilly area of the Loess Plateau, China. Land Degradation and Development, 17(5): 453-465. doi: 10.1002/Idr.701

Guo L B, Gifford R M, 2002. Soil carbon stocks and land use change: A meta analysis. Global Change Biology, 8(4): 345-360. doi: 10.1046/j.1354-1013.2002.00486.x

Guo Shengli, Ma Yuhong, Chen Shengguo et al., 2009. Effects of artificial and natural vegetations on litter production and soil organic carbon change in Loess Hilly Area. Scientia Silvae Sinicae, 45(10): 14-18. (in Chinese)

Hishi T, Hirobe M, Tateno R et al., 2004. Spatial and temporal patterns of water-extractable organic carbon (WEOC) of surface mineral soil in a cool temperate forest ecosystem. Soil Biology and Biochemistry, 36(11): 1731-1737. doi: 10.1016/ j.soilbio.2004.04.030

Hooper D U, Bignell D E, Brown V K et al., 2000. Interactions between aboveground and belowground biodiversity in terrestrial ecosystems: Patterns, mechanisms, and feedbacks. BioScience, 50(12): 1049-1061. doi: 10.1641/0006-3568(2000) 050[1049:IBAABB]2.0.CO;2

$\mathrm{Hu} \mathrm{C}$ J, Fu B J, Liu G H et al., 2010. Vegetation patterns influence on soil microbial biomass and functional diversity in a hilly area of the Loess Plateau, China. Journal of Soils and Sediments, 10(6): 82-1091. doi: 10.1007/s11368-010-0209-3

IPCC (Intergovernmental Panel on Climate Change), 2000. Land Use, Land-use Change, and Forestry. Cambridge: Cambridge University Press.

Lal R, 2002. Soil carbon sequestration in China through agricultural intensification, and restoration of degraded and desertified ecosystems. Land Degradation and Development, 13(6): 469-478. doi: 10.1002/1dr.531

Lal R, 2003. Soil erosion and the global carbon budget. Environment International, 29(4): 437-450. doi: 10.1016/ S0160-4120(02)00192-7

Lal R, 2004. Soil carbon sequestration to mitigate climate change. Geoderma, 123(1): 1-22. doi: 10.1016/j.geoderma.2004.01. 032

Lal R, 2005. Forest soils and carbon sequestration. Forest Ecology and Management, 220(1-3): 242-258. doi: 10.1016/j. foreco.2005.08.015

Lemenih M, Itanna F, 2004. Soil carbon stock and turnovers in various vegetation types and arable lands along an elevation gradient in southern Ethiopia. Geoderma, 123(2): 177-188. doi: 10.1016/j.geoderma.2004.02.004

Li Hongsheng, Liu Guangquan, Wang Hongzhe et al., 2008. Seasonal changes in soil respiration and the driving factors of four woody plant communities in the Loess Plateau. Acta Ecologica Sinica, 28(9): 4009-4106. (in Chinese)
Li Rong, Li Yong, Li Junjie et al., 2008. A preliminary study on soil respiration of eroded sloping land in Chines Loess Plateau. Chinese Journal of Agrometeorology, 29(2): 123-126. (in Chinese)

Lloyd J, Taylor J A, 1994. On the temperature dependence of soil respiration. Functional Ecology, 8(3): 315-323. doi: 10.2307/ 2389824

Lu Rukun. 1999. Analytical Methods for Soil and Agricultural Chemistry. Beijing: China Agricultural Science and Technology Press. (in Chinese)

Palma R M, Arrigo N M, Saubidet M J, 2000. Chemical and biochemical properties as potential indicators of disturbances. $\mathrm{Bi}$ ology and Fertility of Soils, 32(5): 381-384. doi: 10.1007/s003740000266

Peng Wenying, Zhang Keli, Yang Qinke, 2006. Forecast of impact of the returning farms to forests on soil organic carbon of Loess Plateau. Areal Research and Development, 25(3): 94-99. (in Chinese)

Post W M, Kwon K C, 2000. Soil carbon sequestration and land-use change: Processes and potential. Global Change Biology, 6(3): 317-327. doi: 10.1046/j.1365-2486.2000. 00308.x

Raich J W, Tufekcioglu A, 2000. Vegetation and soil respiration: Correlations and controls. Biogeochemistry, 48(1): 71-90. doi: 10.1023/A:1006112000616

Resh S C, Binkley D, Parrotta J A, 2002. Greater soil carbon sequestration under nitrogen-fixing trees compared with Eucalyptus species. Ecosystems, 5(3): 217-231. doi: 10.1007/s 10021-001-0067-3

Schlesinger W H, 1997. Biogeochemistry: An Analysis of Global Change (2nd ed.). California San Diego: Academic Press.

Scott N A, Tate K R, Ford-Robertson J et al., 1999. Soil carbon storage in plantation forests and pastures: Land-use change implications. Tellus, 51(2): 326-335. doi: 10.1034/j.16000889.1999.00015.x

Singh B K, Bardgett R D, Smith P et al., 2010. Microorganisms and climate change: Terrestrial feedbacks and mitigation options. Nature, 8: 779-790. doi: 10.1038/nrmicro2439

Smith P, 2008. Land use change and soil organic carbon dynamics. Nutrient Cycling Agroecosystems, 81(2): 169-178. doi: 10.1007/s10705-007-9138-y

Smith P, Martino D, Cai Z C et al., 2008. Greenhouse gas mitigation in agriculture. Philosophical Transactions of the Royal Society Biological Sciences, 363(1492): 789-813. doi: 10.1098/rstb.2007.2184

Vesterdal L, Ritter E, Gundersen P, 2002. Change in soil organic carbon following afforestation of former arable land. Forest Ecology and Management, 169(1-2): 137-147. doi: 10.1016/ S0378-1127(02)00304-3

Wang J, Fu B J, Qiu Y et al., 2001. Soil nutrients in relation to land use and landscape position in the semi-arid small catchment on the Loess Plateau in China. Jorunal of Arid Environments, 48(4): 537-550. doi: 10.1006/jare.2000.0763

Wang Xiaoli, Guo Shengli, Ma Yuhong et al., 2007. Effects of land use type on soil organic $\mathrm{C}$ and total $\mathrm{N}$ in a small water- 
shed in loess hilly-gully region. Chinese Journal of Applied Ecology, 18(6): 1281-1285. (in Chinese)

Wardle D A, Bardgett R D, Klironomos J N et al., 2004. Ecological linkages between aboveground and belowground biota. Science, 304(5677): 1629-1633. doi: 10.1126/science. 1094875

Wildung R E, Garland T R, Buschbom R L, 1975. The interdependent effects of soil temperature and water content on soil respiration rate and plant root decomposition in arid grassland soils. Soil Biology and Biochemistry, 7(6): 373-378. doi: 10.1016/0038-0717(75)90052-8

Wu Y Q, Liu G H, Fu B J, 2006. Comparing soil $\mathrm{CO}_{2}$ emission in pine plantation and oak shrub: Dynamics and correlations.
Ecological Research, 21(6): 840-848. doi: 10.1007/s11284006-0040-x

Yang Guang, Rong Liyuan, 2007. Effects of artificial vegetation types on soil moisture, carbon and nitrogen in the hilly and gully area of the Loess Plateau. Bulletin of Soil and Water Conservation, 27(6): 30-33. (in Chinese)

Zhang K, Dang H, Tan S et al., 2009. Change in soil organic carbon following the 'Grain for Green' programme in China. Land Degradation and Development, 21(1): 13-23. doi: 10.1002/1dr.954

Zheng F L, 2006. Effect of vegetation changes on soil erosion on the Loess Plateau. Pedosphere, 16(4): 420-427. doi: 10.1016/ S1002-0160(06)60071-4 